\title{
Medo, honra e marginalidade: imagens de Jacob Patacho na história e literatura do século XIX
}

\author{
Aldrin Moura de Figueiredo
}

\section{RESUMO}

Este artigo analisa as interaçóes entre narrativas da história e da literatura a respeito dos acontecimentos deflagrados na Província do Grão-Pará durante a primeira metade do século XIX, envolvendo a figura do soldado desertor Jacob Patacho. Algumas açôes do chamado "cangaceiro das águas", supostamente responsáveis por "aterrorizar" as populaçôes moradoras dos rios e igarapés da região amazônica no início da década de 1830, ultrapassaram a memória oficial e popular da época, chegando à literatura e aos compêndios de história. De modo geral, essas narrativas e memórias foram vinculadas aos estigmas da "violência" e da "criminalidade". Essa associação, aparentemente despretensiosa, contribuiu para fixar na historiografia brasileira uma visão específica das populaçóes pobres e escravas do Pará durante o Segundo Reinado, marcada pelo sentimento do medo.

Palavras-chave: marginal; medo; História; Literatura; século XIX.

\section{ABSTRACT}

This paper analyzes the interactions between historical and literary narratives in the Province of Grão-Pará throughout the first half of the nineteenth century, involving the figure of the defector Jacob Patacho. Some of the actions of the so-called cangaceiro das águas (bandit of the waters), allegedly responsible for "terrorizing" the populations residing in the rivers and streams of the Amazon region in the early 1830s, exceeded the official and popular memory of the time, coming to literature and history books. In general, these narratives and memories were linked to the stigma of "violence" and "crime." This apparently unpretentious association contributed to settle a specific view, marked by a sense of fear, of the poor and the slave populations in Pará during the Second Empire in Brazilian historiography.

Keywords: marginal; fear; History; Literature; nineteenth century.

DOI - http://dx.doi.org/10.1590/2237-101X0173210

Artigo recebido em 30 de junho de 2015 e aprovado para publicação em 31 de janeiro de 2016.

* Universidade Estadual de Campinas, Campinas, SP, Brasil

Doutor em História (Unicamp, 2001) e bolsista de produtividade do CNPq. Atualmente é professor do Programa de Pós-Graduaçáo em História Social da Amazônia e diretor do Centro de Memória da Amazônia, sediado na Universidade Federal do Pará. 
No decorrer do Segundo Reinado, quando o processo de lutas sociais e políticas deflagradas no Pará na década de 1830 já se constituía em acontecimentos presentes, um nome era infalível nas memórias e narrativas: Jacob Patacho, vulgo "marginal", "facínora", "celerado", "chefe de bando", "cangaceiro das águas" e outras alcunhas que o tempo levou. Suas açôes foram empreendidas nos rios e igarapés da Amazônia pouco tempo antes da Cabanagem (1835-1840) e grande parte do que se disse ou se revelou sobre sua personalidade, seu caráter, suas façanhas e sua história, está entrelaçada em um constante sentimento de medo.

As diferentes e reiteradas imagens de Jacob Patacho fazem parte da construção narrativa da própria história política do Grão-Pará nas décadas de 1820 e 1830. Eis um tempo irremediavelmente ligado às lutas da independência do Brasil e às origens da Cabanagem (18351840) como baliza da própria história sobre a Amazônia brasileira. Dito de outra maneira, a história de personagens como Patacho permite compreender uma questão mais ampla que é como os chamados "tempos amotinados" ou do "vulcão da anarquia" aparecem na produção intelectual do século XIX. ${ }^{1}$ Aqui, porém, nosso interesse versa mais sobre a construção da imagem do indivíduo e do sujeito como emblema da ação histórica que, pese o constante diálogo com os quadros mais amplos da política e da sociedade, pode trazer luz ao debate sobre a composição de personagens históricos sob o ângulo da literatura e da própria narrativa historiográfica.

Ao ser primeiramente lembrado como marginal, Patacho oscila entre o herói de uma legenda e um sujeito que foi posto na "exclusão" e na "margem" do centro dominante da história. Jean-Claude Schmitt ensina que marginais são, via de regra, homens e mulheres que, ao longo da história, tem aparência e atitude consideradas fora de padróes chamados "normais". ${ }^{2}$ São tipos transitórios ou permanentemente afastados do meio social, como os loucos, mendigos, ciganos, praticantes de heresias, operários, prostitutas, negros, índios, bandidos e pobres. Nessa ambiguidade toda, porém, havia uma biografia narrada, constantemente reiterada pelas lembranças, pela literatura ou pelo próprio registro da história.

Segundo Henrique Jorge Hurley, historiador e presidente do Instituto Histórico e Geográfico do Pará (IHGP) na década de 1930, Jacob Patacho (Jacob Pedro Borges), foi um soldado desertor das tropas "legais" que, no início da década de 1830, se uniu a outro soldado desertor chamado Saraiva e formou um bando "marginal" composto por índios e caboclos. Hábeis no comando de canoas, botes e montarias, o grupo de malfeitores passou a atuar nos rios e igarapés localizados no interior do Pará, cometendo os mais diversos crimes. Em 1832, por intermédio do padre João Venâncio de Britto, quase todos os integrantes do bando foram presos ou mortos na localidade de Baiáo, com exceção do líder Jacob Patacho que, ao refugiar-se em Belém, também acabou sendo capturado e recolhido à Fortaleza da

\footnotetext{
${ }^{1}$ PINA, Maria das Graças G. de. Cabanagem: "o vulcáo da anarquia"?. Labirintos, v. 1, p. 1-14, 2008.

2 SCHMITT, Jean-Claude. A história dos marginais. In: LE GOFF, J.; CHARTIER, Roger (Orgs.). A história nova. 5. ed. São Paulo: Martins Fontes. 2005, p. 352-390. p. 354
} 
Medo, honra e marginalidade: imagens de Jacob Patacho na história e literatura do século XIX

\section{Aldrin Moura de Figueiredo}

Barra pelo capitáo Affonso de Albuquerque Mello, comandante da Guarda Municipal. Em 1835, com a invasáo de Belém pelos cabanos, ${ }^{3}$ Patacho e seu amigo Saraiva foram libertados juntamente com os demais presos da capital. No ano seguinte, já refugiado na cidade de Cametá, planejou tomar o poder na cidade, mas uma tropa enviada pelo marechal Soares Andrea conseguiu debelar a ação dos supostos "rebeldes". Ao ser novamente aprisionado e enviado para Belém, Jacob Patacho acabou morrendo, meses depois, no hospital onde estavam recolhidos os doentes de varíola.

Concorrendo historicamente, em termos de "popularidade" regional do século XIX, com as próprias lideranças do chamado movimento cabano, Jacob Patacho não foi descrito nos documentos oficiais ou bibliográficos como portador dos traços revolucionários ou políticos geralmente atribuídos a lideranças rebeldes como Batista Campos, José Malcher, Francisco Vinagre e Eduardo Angelim. Sua "notoriedade", segundo os escritos de alguns estudiosos e a documentação oficial produzida na época, advinha de "feitos", que, na concepção dos literatos e homens de governo, nada tinham de heroísmo ou patriotismo, representando ações violentas de alguém que supostamente se beneficiou do processo de convulsão social para cometer "crimes" diversos.

Ignacio Accioly Cerqueira e Silva, autor da primeira corografia do Pará no século XIX, chamou Jacob Patacho de "celerado", "facínora"; o político e historiador Domingos Antônio Rayol o evocou como "facínora" e como "malvado". Já nas primeiras décadas do século XX, a percepção sobre os feitos de Patacho em nada tinha mudado. Jorge Hurley, em estudo

\footnotetext{
${ }^{3}$ A Cabanagem (1835-1840) se constituiu em um movimento político e social, deflagrado na Província do Grão-Pará, com forte participação de caboclos, negros e índios, que ameaçou a manutenção do poder imposto pelo governo central sobre a região. As lutas foram iniciadas em $\underline{6 \text { de janeiro }}$ de $\underline{1835}$, quando o quartel e o palácio do governo de Belém foram conquistados pelos rebeldes, sob liderança Antônio Vinagre. Durante esse processo, o então presidente da província Lobo de Souza foi assassinado e substituído por José Clemente Malcher. Porém, em razão de divergências internas, Malcher foi rapidamente deposto, sendo sucedido na presidência por Francisco Vinagre, e finalmente, por Eduardo Angelim, que comandou os rebeldes cabanos durante alguns meses, até a repressão, enviada pelo governo central, sob comando do Marechal Francisco José Soares Andréa, destruir o movimento, deixando mais de 30 mil mortos. Para mais informaçóes ver estudos clássicos como: HURLEY, Henrique Jorge. A Cabanagem. Belém: Livraria Clássica, 1936; CRUZ, Ernesto. Nos bastidores da Cabanagem. Belém, Oficina Gráfica da Revista de Veterinária, 1942; ROCQUE, Carlos. Cabanagem: epopéia de um povo. Belém: Imprensa Oficial, 1984; CHIAVENATO, José Júlio. Cabanagem: o povo no poder. São Paulo: Brasiliense, 1984; DI PAOLO, Pasquale. Cabanagem: a revoluçáo popular da Amazônia. 2. ed. Belém: Cejup, 1990. Magda Ricci, Luiz Balkar Pinheiro e, mais recentemente, Mark Harris realizaram revisóes importantes da historiografia da cabanagem sob diferentes perspectivas. Cf. RICCI, Magda. Do sentido aos significados da Cabanagem: percursos historiográficos. Anais do Arquivo Público de Belém, Belém, v. 4, p. 241-271, 2001; PINHEIRO, Luiz Balkar. Visóes da Cabanagem: uma revolta popular e suas representaçóes na historiografia. Manaus: Valer, 2001 e HARRIS, Mark. Rebellion on the Amazon: the Cabanagem, race, and popular culture in the north of Brazil, 1798-1840. Cambridge: Cambridge University Press, 2010.

${ }^{4}$ CERQUEIRA E SIVA, Ignacio Accioli de. Corografia Paraense ou Descrip̧̧ão Física, Historica, e Politica da Provincia do Gram-Pará. Salvador: Typografia do Diario, 1833, p. 230

${ }^{5}$ RAIOL, Domingos Antônio. Motins Políticos ou História dos Principais Acontecimentos Políticos na Província do Pará desde o ano de 1821 até 1835. v. II. São Luís: Typ. B. de Mattos, 1868, p. 189-192.
} 
para o IHGP publicado em 1938, deu-lhe a alcunha de "fera" humana, ${ }^{6}$ acrescendo-lhe as proezas de "cangaceiro das águas", 7 que "dentro de um século, felizmente, não conseguiu imitadores". A vilania e o banditismo que compunham a imagem de anti-herói estavam também associados aos espaços sociais e geográficos que percorriam. O contexto amazônico pode ser analisado, neste sentido, a partir de questôes postas sobre outras épocas e outras realidades históricas, levando-se em conta as diferenças de tempo e espaço. Bandidos, reitera Eric Hobsbawm, agiam em "áreas remotas (...) como florestas ou estuários, com seu labirinto de canais e cursos d'água". 'Distantes do centro de poder, mas ao mesmo tempo sua órbita, esses marginais, sugere Delumeau, sempre foram identificados pelas autoridades "como uma ameaça para a ordem estabelecida", ${ }^{10}$ assim como no Pará, por simbolizarem o risco da subversão e da violência nas cidades e áreas rurais da Amazônia.

O momento também era conturbado na história da Amazônia. O processo de lutas sociopolíticas no Grão-Pará, deflagrado nas décadas de 1820 e 1830, desencadeou, na imensa área da planície equatorial, a ação de diversos grupos armados compostos por mestiços, índios e negros, então vistos como malfeitores, criminosos e assassinos capazes de se aproveitar das "desordens" propiciadas pelas "perturbaçôes políticas e as guerras". ${ }^{11} \mathrm{Na}$ "menoridade" do imperador do Brasil, o banditismo teria se transformado em profusão de delitos diversos, adequando-se à perspectiva de que o "banditismo pode preludiar ou acompanhar movimentos sociais de vulto". ${ }^{12}$ A história e a "lenda" de Jacob Patacho não são por outra razão vistas como um prelúdio da Cabanagem.

Durante os primeiros anos da década de 1830, chamados de pré-Cabanagem, quando o Grão-Pará passava por um processo de convulsão político-social, a criminalidade proliferava. Alguns historiadores, como Jean-Claude Schmitt, têm proposto que, em situações análogas à paraense, a "liberdade de matar e de saquear" servir, sem dúvida, de atração a "muitos marginais". ${ }^{13}$ Jacob Patacho foi descrito ainda em vida como um tipo "especial" de bandido, aquele cujas "façanhas" ultrapassam os limites da documentaçáo oficial, das no-

\footnotetext{
${ }^{6}$ HURLEY, Henrique Jorge. Os cangaceiros das águas, Jacob Patacho. Revista do Instituto Histórico e Geographico do Pará, v. 10, p. 219, 1938.

${ }^{7} \mathrm{Na}$ década de 1930, quando o movimento do cangaço deflagrado no Nordeste brasileiro, ganhava notoriedade nacional, o historiador Henrique Jorge Hurley, adaptou esse conceito para a regiáo amazônica da primeira metade do século XIX, aplicando o termo "cangaceiro das águas" para Jacob Patacho e seu "grupo criminoso", prática que de acordo com Hurley, foi extinta com o fim do próprio bando, pois "morreu com ele a semente do cangaceirismo das águas, que ele lançou de bubuia nas águas do Tocantins”. Para maiores informaçóes ver: HURLEY, 1936; 1936a; 1938; 1938a.

${ }^{8}$ HURLEY, Henrique Jorge. Os cangaceiros das águas, op. cit., p. 213.

${ }^{9}$ HOBSBAWM, Eric. Bandidos. 4. ed. Sáo Paulo: Paz e Terra, 2010, p. 41.

${ }^{10}$ DELUMEAU, Jean. História do medo no ocidente 1300-1800: uma cidade sitiada. Sáo Paulo: Companhia das Letras, 2009, p. 297.

${ }^{11}$ HOBSBAWM, Eric. Bandidos, op. cit., p. 43.

${ }^{12}$ Ibidem, p. 44.

${ }^{13}$ SCHMITT, Jean-Claude. A história dos marginais, op. cit., p. 382.
} 
Medo, honra e marginalidade: imagens de Jacob Patacho na história e literatura do século XIX

Aldrin Moura de Figueiredo

tas de jornais e do imaginário popular, ganhando referências em narrativas históricas e até mesmo em um conto literário. Assim, as supostas açóes desse "criminoso" foram delineadas em três momentos distintos do século XIX por alguns expoentes da intelectualidade nacional, Ignacio Accioli de Cerqueira e Silva, ${ }^{14}$ Domingos Antônio Raiol ${ }^{15}$ e Herculano Marcos Inglês de Sousa. ${ }^{16}$

Em 1833, Jacob Patacho, o "celerado", aparece no estudo intitulado Corografia paraense ou Descripção Física, Historica, e Politica da Provincia do Gram-Pará, de Ignacio Accioli de Cerqueira e Silva, estudo esse que trata "minuciosamente da situação da Província do Pará, entre o fim da época colonial e o limiar da nova situação política 'distante' de Portugal”, 17

${ }_{14}$ Ignacio Accioli de Cerqueira e Silva nasceu em Coimbra (Portugal) em 1808, filho do desembargador
Miguel Joaquim Cerqueira e Silva. Estudou na Universidade de Coimbra, mas náo concluiu o curso. Ainda
criança veio para o Brasil em companhia de seu pai, se estabelecendo inicialmente no Pará, onde ficou por
aproximadamente 13 anos, fixando depois residência na Bahia. Entre suas principais obras destacam-se a
Corografia Paraense (1833), As Memorias historicas e politicas da provincia da Bahia (1835), Informaçáo ou
descripçâo topographica e politica do rio de São Francisco (1847), Ensaio Chorographico do Imperio do Brazil (1853). Faleceu no Rio de Janeiro em 1865. Cf. FIGUEIREDO, Aldrin Moura de. Teias da memória: a Companhia de Jesus e a historiografia da Amazônia no século XIX. Varia Historia, Belo Horizonte, n. 23, p. 77-96, 2000.

${ }^{15}$ Domingos Antônio Raiol era filho de Pedro Antônio Raiol e de Dona Archangela Maria da Costa Raiol, nascido em Vigia, no dia 4 de março de 1830. Aos 5 anos, em razáo das lutas deflagradas durante a Cabanagem, ficou órfão. Seu pai, então vereador do Conselho Municipal da Vigia, foi morto pelos rebeldes cabanos em 23 de julho de 1835. Protegido por Bernardo de Souza Franco, primeiro presidente da província do Pará após o término do movimento rebelde, estudou Humanidades em Belém, seguindo depois para Recife onde se bacharelou em Direito em 1854. Além de extensa vida política pelo Partido Liberal e em favor da monarquia, foi agraciado com o título de Barão de Guajará, por carta imperial de 3 de março de 1883. Faleceu em Belém, em 29 de outubro de 1912. Sua obra Motins Políticos ou História dos Principais Acontecimentos Políticos na Província do Pará desde o ano de 1821 até 1835, publicada inicialmente em cinco tomos, ao longo de 1865 a 1890, tornou-se a principal fonte para o estudo do movimento cabano. Cf. LIMA, Luciano Demetrius B. Motins Políticos e a historiografia imperial: a inserção de um intelectual amazônico nos quadros do IHGB. Almanack Braziliense, v. 12, p. 88-104, 2010.

${ }^{16}$ Herculano Marcos Inglês de Sousa nasceu em 28 de dezembro de 1853, no município de Óbidos, no Estado do Pará. No ano de 1867, seguiu para o Rio de Janeiro a fim de cursar o ensino secundário, onde estudou em regime de internato no Colégio Perseverança. No decurso de sua vida escolar, com apenas 14 anos, escreveu algumas produçóes juvenis, confiscadas pelo diretor do colégio em que estudava. Em 1870, Inglês de Sousa seguiu para a cidade de Recife-PE, onde ingressou na Faculdade de Direito. Cursou quatro anos de estudo e depois transferiu-se para São Paulo, onde concluiu o curso no ano de 1876. Sob o pseudônimo de Luís Dolzani, publicou seus primeiros trabalhos: O cacaulista (1876), Cenas da vida do Amazonas: história de um pescador (1876), e O coronel sangrado (1877), na cidade de Santos. Após sua formação em Direito, dedicou-se predominantemente à política, sendo presidente (governador) da Província de Sergipe (1881) e do Espírito Santo (1882). A partir do ano de 1883, Inglês de Sousa abandonou a carreira política e engajou-se na advocacia, chegando a ministrar aulas na área de Direito Comercial e escrever obras direcionadas ao meio jurídico. Em 1891 publica a obra $O$ missionário, e posteriormente Contos amazônicos (1893), sua última obra, dedicada ao amigo Sílvio Romero. Faleceu no dia 6 de setembro de 1918, aos 65 anos de idade, na cidade do Rio de Janeiro, onde passou a maior parte de sua vida. Cf. ARAÚJO, José Mourão de. Literatura e história na recepção crítica do conto de Inglês de Sousa. Dissertação (Letras) - Universidade Federal do Pará, 2006.

${ }^{17}$ FIGUEIREDO, Aldrin Moura de. Teias da memória: a Companhia de Jesus e a historiografia da Amazônia no século XIX. Varia Historia, Belo Horizonte, n. 23, p. 78, 2000. 
almejando compreender o "modo pelo qual o passado da regiấo influenciava a situação presente". ${ }^{18}$ Em 1868, o famoso "fera" reaparece no segundo tomo do estudo histórico do bacharel e deputado paraense Domingos Antônio Raiol (barão de Guajará), denominado Motins politicos, que enfoca o processo de lutas sociopolíticas no Grão-Pará, entre as décadas de 1820 e 1830. Aparece também em 1893, quando as açóes de Jacob Patacho extrapolaram as narrativas históricas, sendo inserida no conto "A Quadrilha de Jacob Patacho", de autoria do paraense Inglês de Sousa, que integra a obra Contos amazônicos, constituída em diversas narrativas curtas, possuindo como uma de suas características a apresentaçáo de um universo cultural e social próprio do homem amazônico, bem como a aproximaçáo das personagens (geralmente caboclos) em suas experiências na floresta e rios da região.

O conto de Inglês de Sousa aborda o ataque do "bando criminoso" comandado por Jacob Patacho ao sítio de Félix Salvaterra, localizado às margens do rio Tapajós. O literato entrelaça elementos históricos e ficcionais com o intuito de narrar as açôes do "cangaceiro das águas" e de seus seguidores com ares de suspense e dramaticidade, transformando o sentimento de medo, vivenciado por alguns personagens, em um dos elementos principais da narrativa. Isso quer dizer, em outras palavras, que a própria narrativa intelectual pode ser um elemento fundamental na "construção do paradigma da violência". ${ }^{19}$ Este tema viria a ser importantíssimo para a historiografia contemporânea, especialmente a partir de 1932, quando foi publicado o livro de Georges Lefebvre sobre o "grande medo" de 1789, em que a imagem de desempregados, errantes, pobres se fundem a imagens da fome e da miséria num contexto de conturbação social e política. ${ }^{20}$ No entanto, o enfoque dos intérpretes da história da Jacob Patacho não encontrou grandes contestaçôes no meio intelectual brasileiro do século XIX e até favoreceu os argumentos em favor da estigmatização das açôes do "cangaceiro das águas". O tempo também não foi páreo para a memória. As imagens do "bandido" passaram pelo contexto das Regências e do Segundo Reinado até chegarem aos primeiros anos da República, considerado um propiciador de comportamentos "brutais" na sociedade paraense dos tempos da Cabanagem.

Jean Delumeau afirma que "nada é mais difícil de analisar que o medo". ${ }^{21}$ Para esse historiador, a principal dificuldade reside na especificidade e no caráter ambíguo do estudo de um sentimento no âmbito do medo coletivo ou ainda na "passagem do singular para o plural". ${ }^{22}$ Aqui, revolvemos narrativas do século XIX que, ao descreverem as açôes de um célebre bandido, deixavam transparecer as inseguranças e temores morais, políticos e sociais,

\footnotetext{
${ }^{18}$ Ibidem, p. 78.

${ }^{19}$ AZOULAY, Vincent; BOUCHERON, Patrick (Dir.). Le mot qui tue: une histoire des violences intellectuelles de l'antiquité à nos jours. Seyssel: Champ Vallon, 2009, p. 7.

${ }^{20}$ LEFEBVRE, Georges. O grande medo de 1789: os camponeses e a Revolução Francesa. Rio de Janeiro: Campus, 1979.

${ }^{21}$ DELUMEAU, Jean. História do medo no ocidente 1300-1800, op. cit., p. 29.

${ }^{22}$ Ibidem, p. 30.
} 
vivenciados pelas elites brasileiras durante o século XIX. Nessa lógica, o uso do termo medo circula entre as informaçôes, documentos e memórias do passado e a própria interpretação e leitura dos autores, entre a experiência pessoal e o mais amplo caleidoscópio de emoçóes que vai do temor e à apreensão ante a noção de um perigo real ou imaginário. Está claro que cada texto a ser analisado representa também uma mostra, uma percepção, um olhar e um campo de distinçâo de um grupo, para além da especificidade das reaçôes pessoais narradas pela memória.

Além dessas questôes, é importante ressaltar que em um estudo que objetiva realizar uma abordagem do ponto de vista da história, o uso de uma narrativa ficcional, como as narrativas literárias da Cabanagem, significa, já de início, adotar um pressuposto necessariamente materialista de análise. Acreditamos que, neste aspecto, tanto a obra de Cerqueira e Silva, como a de Raiol, e mesmo os contos de Inglês de Sousa são marcados por evidências históricas objetivamente determinadas — isto é, situadas no movimento do tempo e da cultura. ${ }^{23}$ Daí, certamente, nosso interesse em compreender os aspectos específicos do discurso e da narrativa literária, nos padrôes de intençâo de quem os produziu, ou seja, como um documento a ser devidamente interrogado. Nos parece bastante aceitável, como insiste Antonio Candido, que todo "texto, artístico ou não, ficcional ou não", projeta "contextos objetuais 'puramente intencionais", que podem referir-se ou não a objetos "autônomos", ${ }^{24} \mathrm{e}$ que as mesmas narrativas, portadoras de "objetualidades puramente intencionais" desempenham "certa tendência a se constituírem como realidade". ${ }^{25}$ Sem serem reduzidos à mera documentalidade, tanto o texto histórico como o literário são documentos relevantes na crítica da história. Com efeito, o conto de Inglês de Sousa, como documento, revela também uma interpretação da história da Amazônia sob o viso literário. A simbologia do medo, da perda da propriedade privada, da morte pelo fogo, dos assassinatos e da violência ganhou, na pena dos intelectuais, o peso de suas imagens, de seus sentimentos e de seu saber-fazer textual. ${ }^{26}$

\section{O medo da morte e da desonra}

O sentimento de medo em relação às açóes de Jacob Patacho e seu "bando criminoso", presente nas narrativas da história e da literatura, pode ser visto como uma imagem que prenuncia desgraça e infortúnio. Morrer desonrado era pior do que a pobreza. A tragédia da revoluçáo soava como a da dignidade para as nobres famílias paraenses. $\mathrm{O}$ passado de esplendor e glória parecia por um fio diante de uma profecia que levasse a probidade do chefe

\footnotetext{
${ }^{23}$ WILLIAMS, Raymond. Problems in materialism and culture: selected essays. Londres: Verso, 1980.

${ }^{24}$ CANDIDO, Antonio et al. A personagem de ficção. São Paulo: Perspectiva, 2009, p. 15.

${ }^{25}$ Ibidem, p. 16.

${ }^{26}$ CHAUVAUD, Frederic (Dir.). Corps saccagés: une histoire des violences corporelles du siècle des lumières à nos jours. Rennes: Presses Universitaires de Rennes, 2009.
} 
da casa, a retidão da mulher, e graça, mercê e distinção dos filhos. No livro Corografia paraense, para demonstrar o clima de insegurança vivenciado pelos moradores da comunidade de Cametá no Grão-Pará, Cerqueira e Silva descreve quando um "bando" com "mais de trinta desertores e criminosos" capitaneados por Jacob Patacho, acometeram aquele povoado no silêncio da noite, apoderaram-se do Trem de Guerra, prenderam o juiz de paz, assassinaram dois indivíduos, além de esperarem o "aparecimento do dia para praticarem maiores desatinos". ${ }^{27}$

O que Cerqueira e Silva descreve é um clima de insegurança e medo que vai muito além das fronteiras do Pará e do Brasil. O que acontecia na pequena Cametá de fato reverberava as tensôes que aconteciam no Império Brasileiro e em Portugal. Não é à toa que tanto Cametá como a cidade do Porto, em Portugal ganhariam logo a seguir o título de "Cidade Invicta". Em 1832, a cidade do Porto foi palco da guerra civil portuguesa quando D. Miguel sitiou a cidade por mais de um ano na tentativa de vencer seu irmão D. Pedro IV de Portugal, e I do Brasil. A resistência das tropas de D. Pedro e dos cidadãos do Porto foram tomadas pela memória como ato heroico. A rainha, D. Maria II de Portugal, concedeu o título de Invicta à cidade do Porto. No rastro da memória portuense, Cametá ganhou honra comparável por se defender dos cabanos e dos "bandos" de malvados durante os episódios e motins da década de 1830. A defesa da honra era, portanto, assunto do indivíduo, da coletividade e da naçáo. ${ }^{28}$

O sentimento de risco de vida, e do medo das agressóes físicas cometidas pela quadrilha do soldado desertor foi assunto das rodas domésticas, dos jornais da época, dos debates parlamentares. Ao mesmo tempo, como invicta ficou a vila de Cametá, foi se construindo a memória da defesa da honra. A narrativa do fracasso do bandido, da derrota do marginal diante da reação dos moradores em defesa de sua integridade e honra ganhou notoriedade. É o mesmo Cerqueira e Silva quem comenta que os agressores acabaram "cedendo à força maior" e, mesmo "com mortes de parte a parte", terminaram optando pela fuga e pela debandada geral. ${ }^{29}$ Com efeito, o assunto da crônica histórica trazia à baila um tema muito importante para a política, para o direito e para a sociedade da primeira metade do século XIX, a importância de conceito de "honra" para a cultura em contraste com o sentimento de "direito" para uma sociedade pautada em noçôes de civilização e construção da nacionalidade.

Autores, como William Read, demonstram a emergência da velha noção de honra e suas relaçóes com o sentimento de participação política no contexto pós-revolucionário da França. ${ }^{30}$ Mas, longe de apenas ser uma questão de foro íntimo, a honra também esteve associada aos negócios e à riqueza. Mark Häbelein, em recente estudo sobre os Fugger, na Alemanha do Renascimento, mostra como essa família de empresários e financistas chegou

\footnotetext{
${ }^{27}$ CERQUEIRA E SIVA, Ignacio Accioli de. Corografia Paraense, op. cit., p. 230.

${ }^{28}$ FEBVRE, Lucien. Honra e pátria. Rio de Janeiro: Civilização Brasileira, 1998, p. 195.

${ }^{29}$ CERQUEIRA E SIVA, Ignacio Accioli de. Corografia Paraense, op. cit., p. 230.

${ }^{30}$ REDDY, William. The invisible code: honor and sentiment in post revolutionary France, 1814-1848. Berkeley: University of California Press, 1997.
} 
a constituir um dos maiores grupos econômicos nos séculos XV e XVI. A tese é que a defesa da honra esteve, nesse contexto, completamente integrada à busca de riquezas materiais, o que certamente fez com que os Fugger se tornassem, para parte importante da historiografia contemporânea, precursores do capitalismo, ao lado dos Médicis e dos Welser. ${ }^{31}$

Esses estudos, em contraponto com este, fazem ver como foi importante a discussão sobre as leis no contexto das sublevaçóes e as penas aplicadas aos transgressores. Temas clássicos do pensamento do século XVIII, como os das estruturas do Estado para promulgar e aplicar as leis, o contrato social e as tradiçóes políticas estavam no repertório cognitivo da época. A honra, que parece ser algo arcaico, típico de sociedades tradicionais, em oposição ao domínio da lei e da sociedade civil, adquiriu no contexto paraense, segundo indicam essas narrativas, um duplo sentido. Se no contrato social, os membros da sociedade concordam em abrir mão de alguns aspectos de sua liberdade para se defenderem, no entendimento de que transgressores serão apreendidos e punidos pelas leis, na realidade dos acontecimentos históricos, os mesmos cidadãos tiveram que se armar para defender sua riqueza material e sua honra moral..$^{32}$ Um "bandido" como Jacob Patacho acabou como exemplo do fora da lei, inspirador do medo, opositor da amizade e como alguém que cultivava uma reputaçáo por meio de vinganças rápidas e desproporcionais. O grupo de Jacob Patacho simbolizava, deste modo, a pouca ou nenhuma fidelidade a um governo local, provincial ou nacional. Interessante notar que, sob o ponto de vista da teoria política moderna, Patacho é um sujeito do mundo da honra, no qual a aplicação oficial da lei, muitas vezes, permanecia fora do alcance do direito do Estado. ${ }^{33}$

Na obra de Raiol, Jacob Patacho e seu grupo "criminoso" são apresentados inicialmente como integrantes de uma "pequena embarcação tripulada por índios que assaltava e roubava canoas encontradas nas águas do Guajará e outros rios próximos à capital, assassinando as pessoas que lhe opunham resistência". Essa descrição, marcada pela evidência do clima de insegurança, em virtude dos constrangimentos deste "bando", responsável por "alterar o sossego público" na região, se constitui no emblema do sentimento de medo, também vivenciado pelos grupos dominantes, frente às populaçôes "marginais" ao longo do Segundo Reinado. ${ }^{34}$ Para patentear esse mito da malvadeza, a narrativa é minuciosa ao expor os tais "delitos" de Jacob Patacho e seu "bando", cometido na Bahia do Sol, na Ilha das Onças, nos arredores de Belém.

${ }^{31}$ HÄBERLEIN, Mark. The Fuggers of Augsburg: Pursuing Wealth and Honor in Renaissance Germany. Charlottesville: University of Virginia Press, 2012.

${ }^{32}$ Honra, violência e guerra foram questóes postas em analogia na historiografia da modernidade, como um tópico da psico-história. Cf. STRANGE, Carolyn; CRIBB, Robert; FORTH, Christopher (Eds.). Honour, violence and emotions in history. Londres: Bloomsbury, 2014.

${ }^{33}$ AUFDERHEIDE, Patricia Ann. Order and violence: social deviance and social control in Brazil, 17801840. Dissertação (PhD), University of Minnesota, 1976.

${ }^{34}$ RAIOL, Domingos Antônio. Motins politicos, op. cit., p. 189. 
Refere-se que na baia do Sol junto à ilha chamada do queimado ele [Patacho] no mês de outubro se apoderara de uma canoa que passava do distrito de Vigia para a capital, matando a sangue frio quase todas as pessoas que resistiram aos seus criminosos intentos. Eram três homens e duas mulheres que transportavam para o mercado de Belém as suas produçóes. (...) Acometidos inesperadamente ao passarem por aquela paragem, eles muniram-se de terçados e paus, únicos instrumentos que tinham, e se prepararam para repelir os agressores, mas os facínoras lançando mão de suas e sem lhes dar tempo para o menor ato de defesa desfecharamlhes tiros certeiros: momentos depois deram todos a alma a Deus. Os facinorosos não tendo mais que temer, abordaram então a canoa, investiram contra as mulheres, tentando forçalas aos seus fins lascivos. Elas porém opuseram a mais desesperada resistência conseguindo após enérgica luta lançarem-se ao rio, extenuadas e quase sem vestes. (...) Aí mesmo foram perseguidas. Uma d'elas pouco durou; apenas veio à tona d'água para dizer seu ultimo adeus ao mundo. A outra foi presa pelos cabelos, arrastada até a borda da canoa e por fim arremessada para dentro da tolda com infernal alegria. A infeliz só foi abandonada depois de ter servido de pasto aos danados intentos de tais homens. ${ }^{35}$

De tudo o que se expôs, aparece um ingrediente novo no repertório das façanhas de Patacho: a lascívia, que Raiol utiliza para expressar o conteúdo mais libidinoso, lúbrico e desregrado da palavra. O sexo como estupro, a lascívia como desonra, o desregramento como oposição às leis e aos costumes. $\mathrm{O}$ assunto é denso porque revela um sentimento importante na história das sensibilidades, das mentalidades e do próprio uso da legislação e das tradições na Amazônia da primeira metade do século XIX. Georges Vigarello nos ajuda a entender que o estupro durante todo o Antigo Regime foi muito pouco penalizado pela justiça, apesar de ser fortemente condenado pelo direito codificado. ${ }^{36}$

Sobre a Amazônia colonial sabemos ainda muito pouco a respeito da violência sexual contra a mulher, mas parece evidente que havia certa tolerância com algo que nem sequer era conceituado. As leis puniam com muita severidade alguns crimes, especialmente os realizados com derramamento de sangue. Porém, alguns criminosos se beneficiavam com a impunidade produzida pela precariedade do próprio aparelho judiciário. No caso da violência sexual, a violação era punida quase sempre quando o crime era perpetrado contra crianças, por ferir um bem secreto: a inocência da vítima. Porém, ainda carecemos de estudos sobre a condição feminina no Pará colonial, mais ainda sobre a violência sexual. Alguns estudos que se utilizaram de fontes inquisitoriais revelam, no entanto, que no Pará, assim como em outras partes do império português, houve uma relação entre a classe social e a impunidade. ${ }^{37}$

\footnotetext{
${ }^{35}$ Ibid., p. 189-190.

${ }^{36}$ VIGARELLO, Georges. História do estupro: violência sexual nos séculos XVI-XX. Rio de Janeiro: Jorge Zahar, 1998.

${ }^{37}$ MOTT, Luiz. Sexualidade no Brasil Colonial. In: SÁ, Carlos. (Org.). Sexualidade humana. Rio de Janeiro: Revinter, 2000, p. 117-129.
} 
A obra de Raiol sobre os motins políticos das décadas de 1820 e 1830 traz, no entanto, todo o debate no contexto pós-revolução francesa, quando ocorre uma subversão da legislaçáo a partir dos ideais de liberdade. ${ }^{38}$

$\mathrm{O}$ medo da violência e do estupro contra as mulheres e crianças presente na obra de Raiol pode revelar mudanças importantes acerca desses crimes. Neste contexto, como sugere o estudo de Vigarello, a vítima torna-se um sujeito mais independente de seus tutores e do erro moral no qual estava mantida. A legislação é ampliada para comportar uma categorização dos crimes que passa a fazer distinção entre os comportamentos sexuais privados "luxuriosos", tais como a "fornicaçáo ilícita" e a sodomia, e os comportamentos sexuais criminosos que utilizam violência - como o caso narrado a respeito dos estupros cometidos pelo bando de Patacho. Outra mudança digna de nota é a presença constante da voz pública e do testemunho nos processos. ${ }^{39} \mathrm{O}$ próprio conhecimento social do crime ameaçava a "reputação" das mulheres na região, pois, ao mesmo tempo que mutilava e matava vítimas do sexo masculino, muitas jovens, como as descritas por Raiol, corriam o risco de serem "abusadas". Nessa lógica, a narrativa procurava ressaltar em detalhes as circunstâncias em que esses atos de violência foram deflagrados, nos ataques contra vítimas do sexo feminino, enfatizando de forma aparentemente ambígua, sentimentos de humanidade, ternura, simpatia e compaixão. Raiol, como era de praxe na historiografia romântica, marcava seu texto pela inserção de imagens de fragilidade feminina e temor diante da virilidade e lascívia masculina, ou ainda de atos de heroísmo, como das jovens que lutam pela "honra" durante o ataque do "cangaceiro das águas". ${ }^{40}$

Designados de "facínoras", Jacob Patacho e seu grupo "marginal" eram responsabilizados por crimes considerados odiosos, pois deixavam transparecer o clima de desordem e insegurança na província. Esses acontecimentos, reitera Raiol, também eram integrados à "imaginação popular" que, sob a perspectiva do medo, passou a "pintá-lo com cores cada vez mais carregadas". Além disso, a própria ilha onde os crimes foram cometidos também foi transformada em um espaço que, durante algum tempo, indicou o medo por ser considerada um "perigoso coito de malfeitores, e os viajantes passavam distantes dela com temor de supostos homens perversos que lá habitavam; ninguém ousava aproximar-se seguro de suas praias". ${ }^{41}$ Por meio de descriçóes que indicavam o clima de insegurança, pavor e violência que preponderava no Grão-Pará no início da década de 1830, Raiol deixava transparecer sua convicção de que as mortes e estupros, impetrados pelas ações do bando de Patacho, evidenciava indiretamente aquilo que historiadores que se dedicaram ao estudo do sentimento de

\footnotetext{
${ }^{38}$ LIMA, Luciano Demetrius B. Motins Políticos e a historiografia imperial: a inserçáo de um intelectual amazônico nos quadros do IHGB. Almanack Braziliense, v. 12, p. 88-104, 2010.

${ }^{39}$ MATTHEWS, Graham; GOODMAN, San (Eds.). Violence and the limits of representation. Nova York: Palgrave Macmillan, 2013.

${ }^{40}$ RAIOL, Domingos Antônio. Motins politicos. op. cit., p. 189-190.

${ }^{41}$ Ibidem, p. 190.
} 
Medo, honra e marginalidade: imagens de Jacob Patacho na história e literatura do século XIX

"medo" no Ocidente consideram como um dado importante do "temor do povo anônimo (...) tanto na cidade como no campo". ${ }^{42}$ Essa sensação seria também vivenciada, até em maior grau, por parte das elites políticas no Segundo Reinado, que concebiam as populaçôes pobres, indígenas e escravas como elementos de "má natureza", capazes de proporcionar assassinatos e outras violências. ${ }^{43}$

Nesta descrição do "pavor", Raiol reitera o ataque do "bando" a um sítio de Abaeté, quando o proprietário, com o intuito de proteger sua família "não mediu o perigo que corria na luta desigual com esses bandidos, e com a fúria de quem se sente ultrajado (...) ele acometeu os primeiros que ousaram apoderar-se de suas filhas". Durante o processo de luta, em que o pai de família foi morto a tiros, "mulher e filhas (...) evadiram para os matos próximos a casa e desapareceram na escuridão da noite" ${ }^{44} \mathrm{~A}$ imagem da sombra, da penumbra e da escuridão da noite serviu para dar lugar aos sentimentos de desproteção, surpresa e perigo no horror da "duração" do instante do crime. ${ }^{45}$ Ainda de acordo com Raiol, mesmo perseguidos pelas forças militares governamentais ao longo dos rios amazônicos "eles sabiam iludir a vigilância das autoridades territoriais ocultando-se de dia em lugares quase inaccessíveis. Só de noite saíam de seus esconderijos com as cautelas que as circunstâncias aconselhavam para cometer novas depredações e assassínios". ${ }^{46}$

Aqui a situação de medo de morrer desonrado se aproxima da imagem da morte pela ruína do fogo. Do mesmo modo que a literatura romântica oitocentista, também a ópera explorou, como nenhuma outra arte, as sensibilidades e os medos pela morte em chamas ou na defesa da honra. ${ }^{47}$ Em 1896, o compositor italiano Umberto Giordando apresentou em Miláo a ópera Andrea Chenier, baseando-se na vida do poeta André Chénier (1762-1794), executado durante a revolução francesa. No terceiro ato, na ária La Mamma Morta, a personagem Maddalena di Coigny, filha de família nobre, exclama que ficou órfá quando sua mãe foi morta sob o incêndio para salvá-la durante os tumultos da revolução. ${ }^{48}$ Seu canto traz a memória da dor: "Eles mataram minha mãe na porta do meu quarto. Ela morreu e me salvou. Mais tarde, na calada da noite, eu estava com Bersi, quando de repente, num cintilante lampejo de brilho e luzes, estava à minha frente a rua escura!". A cena traduz o sentimento do fim: "Olhei — minha casa da infância estava pegando fogo! Eu estava sozinha, cercada por nada! Fome e miséria. Privação, perigo". ${ }^{49} \mathrm{Da}$ ópera à literatura, da pintura à poesia, no

\footnotetext{
${ }^{42}$ DELUMEAU, Jean. História do medo no ocidente 1300-1800, op. cit., p. 293.

${ }^{43}$ RAIOL, Domingos Antônio. Motins políticos, op. cit., p. 190.

${ }^{44}$ Ibidem, p. 191-192.

${ }^{45}$ BACHELARD, Gaston. L'Intuition de l'instant. Paris: Stock, 1992, p. 11.

${ }^{46}$ RAIOL, Domingos Antônio. Motins políticos, op. cit., p. 190.

${ }^{47}$ SILVA, Renato Martins e. Em defesa da honra: um tema presente na literatura do século XIX. Anais do IV Congresso de Letras da UERJ. São Gonçalo, 2007, p.1-20.

${ }^{48}$ GIORDANO, Umberto. Andrea Chénier: opera in four acts. New York: Opera Orchestra of Nova York, 1984.

${ }^{49}$ Idem.
} 
final do século XIX, o repertório imagético dos contos de Inglês de Sousa fazia parte de uma "fórmula de emoçôes", para lembrar o conceito warburguiano, recentemente recuperado pelo historiador Carlo Ginzburg em sua história das representaçóes artísticas da política. ${ }^{50}$

No conto "A quadrilha de Jacob Patacho", Inglês de Sousa também fez referências ao medo ocasionado entre os moradores da Amazônia pelos supostos assassinatos e crimes sexuais cometidos pelo "cangaceiro das águas". Em um desses momentos, a personagem Anica, filha de Félix Salvaterra, toma conhecimento, por meio de sua mãe, dos atos praticados pela "quadrilha de Jacob Patacho. Eram donzelas raptadas para saciar as paixóes dos tapuios; pais de família assassinados barbaramente; crianças atiradas ao rio com uma pedra no pescoço (...) um quadro interminável de atrocidades inauditas". ${ }^{51} \mathrm{~A}$ palavra donzela não estava ali por acaso. A mudança do antigo uso do termo, no sentido de moça nobre, para o mais corrente no século XIX, como mulher virgem, demarca a força imagética do conto inglesiano. Ao pavor que emerge nos pensamentos de Anica, é preciso adicionar outros relatos, contidos na ficção, nos quais Patacho é apresentado como "o matador, o incendiário, o demônio vivo que tripudiava sobre os cadáveres quentes de suas vítimas", ${ }^{52}$ e Saraiva, o tenente da "quadrilha", era descrito como "o bárbaro violador de virgens indefesas, o bandido cujo nome mal se pronunciava nos serôes das famílias pobres e honradas". ${ }^{53}$ Além disso, a narração expóe o conflito entre a crueldade do "bando criminoso", composto por "tapuios armados de terçados", contra "os três portugueses que heroicamente defendiam seu lar". 54

O acontecido em 1832, recontado literariamente no início da república, também retoma o conteúdo étnico do banditismo cabano. Mark Harris lembra que Jacob Patacho também se escrevia Jacó Pataxo, usando a grafia da língua geral do nehengatu, corrente na Amazônia até a primeira metade do século XIX..$^{5} \mathrm{~A}$ ancestralidade cabocla, tapuia e indígena muitas vezes foi reiterada como prova do rebaixamento moral do personagem. Inglês de Sousa em vários momentos refere o bando de Patacho como um grupo de "tapuios", "mestiços" e "selvagens" com nenhuma compreensão sobre os valores e regras de conduta social e da vergonha que poderiam causar nos pais de família. A humilhação pela vergonha ou por algo que causasse ignomínia, de conteúdo oprobrioso, tal como pensado pelas elites portuguesas parecia não fazer parte do léxico popular da Amazônia. Não foi sem sentido que a histografia do século XX, a partir de autores egressos do modernismo, como Jorge Hurley, Arthur Cézar Ferreira Reis e Ernesto Cruz, recompôs a leitura desse banditismo cabano a partir de outras interpretaçôes. Agora estava em jogo mais do que qualquer conteúdo moral, "as ide-

${ }^{50}$ GINZBURG, Carlo. Medo, reverência e terror: quatro ensaios de iconografia política. São Paulo: Companhia das Letras, 2014.

${ }^{51}$ SOUSA, Inglês de. Contos amazônicos. São Paulo: Editora Martin Claret. 2005. p. 92

${ }^{52}$ Ibidem, p. 92.

53 Ibidem, p. 94.

${ }^{54}$ Ibidem, p. 97.

${ }^{55}$ HARRIS, Mark. Rebellion on the Amazon: the Cabanagem, race, and popular culture in the north of Brazil, 1798-1840. Cambridge: Cambridge University Press, 2010, p. 222. 
ologias políticas que dividiam a família paraense" ${ }^{56} \mathrm{O}$ medo seria um sintoma de problema social e político de raízes muito profundas. Honra e desonra eram paradigmas de um sentimento imerso nos anos de revolução, a partir de códigos sociais nem sempre muito visíveis. ${ }^{57}$ Os registros históricos e literários aqui analisados também procuram demonstrar que os atos do "cangaceiro das águas" e de seu bando representavam, para além da perseguição física a indivíduos, ameaças de subversão à ordem social e política vigente. A atuação de um Jacob Patacho representava a iminência de rebelião das "classes perigosas", da "gente infame" e o "mundo do desgoverno".

\section{À guisa de conclusão}

A história, a memória de Jacob Patacho e as narrativas sobre o medo do bandido parecem trazer à tona aquilo que o historiador Georges Gursdorf chamou de "consciência do presente" ${ }^{58}$ As diferentes imagens apresentadas nas obras de Cerqueira e Silva, com uma visão contemporânea às convulsóes sociopolíticas nas quais Jacob Patacho estava inserido nos anos de 1830, de Domingos Antônio Raiol, que começa a publicar nos anos de 1860 sua monumental obra sobre os motins políticos no Pará, e Inglês de Souza, autor que militou no universo da primeira República, com uma obra publicada na década de 1890, mostram rupturas, permanências e mudanças nos eixos interpretativos da ação histórica no Oitocentos brasileiro. Suas obras estão inseridas nos debates e nas agendas políticas de seu tempo, revelando mesmo a construção, em seus escritos, do personagem Jacob Patacho como passagem das estratégias discursivas lançadas para a elaboração de interpretaçôes mais gerais sobre os motins políticos no Pará nas décadas de 1820 e 1830.

O primeiro "retrato" de Jacob Patacho veio pela pena Ignacio Accioli de Cerqueira e Silva em sua obra de estreia como cronista-mor do Império do Brasil. Ignacio provinha de uma família de projeçáo no judiciário luso-brasileiro em Alagoas, de quem herdou profundo interesse pela história das instituiçôes administrativas e pela organização do sistema jurídico no Brasil. Nascido em Coimbra, Ignacio Accioli de Cerqueira e Silva teve uma educação ilustrada, circulando nos meios teatrais, por volta de 1818, época em que Almeida Garret e outros amigos representavam peças de Voltaire com auxílio das famílias e da maçonaria. ${ }^{59}$

\footnotetext{
${ }^{56}$ REIS, Arthur Cezar Ferreira. Sintese de História do Pará. Belém: Revista de Veterinária, 1942, p. 103. Cf. RICCI, Magda. Do sentido aos significados da Cabanagem: percursos historiográficos. Anais do Arquivo Público de Belém, Belém, v. 4, p. 241-271, 2001.

${ }^{57}$ Uma analogia para o contexto francês da primeira metade do século XIX está em REDDY, William. The invisible code, op. cit.

${ }^{58}$ GURSDORF, Georges. As revoluçôes da França e da América: a violência e a sabedoria. Rio de Janeiro: Nova Fronteira, 1993, p. 5.

${ }^{59}$ FIGUEIREDO, Aldrin Moura de. Teias da memória: a Companhia de Jesus e a historiografia da Amazônia no século XIX. Varia Historia, Belo Horizonte, n. 23, 2000, p. 77-96. SILVA, Renato Martins e. Em defesa da honra: um tema presente na literatura do século XIX, op. cit., p. 1-20.
} 
Apesar de não conhecermos grandes trabalhos sobre a trajetória intelectual e política de Ignacio Accioli é conhecida sua estada no Pará a partir de 1822, quando acompanhou seu pai nas lutas de independência no Pará. Durante os motins de 1822, com apenas quinze anos de idade foi preso juntamente com o pai e ambos remetidos a ferros a Lisboa. No ano seguinte, por ordem de D. João IV foi libertado e remetido novamente ao Brasil. Sua narrativa, portanto, eivada de sentimento e vivência pessoal, traz também a noção de passado como explicaçáo do presente, da história como mestra da vida. A antiga premissa heurística de Cícero, tão em voga na historiografia oitocentista, utilizava os exemplos do passado para ensinar ao presente o peso das mazelas da história. ${ }^{60} \mathrm{Um}$ antimodelo biográfico, como teria sido o de Jacob Patacho, havia de ter um papel importante na construção narrativa da história do Pará. A miséria dos crimes, dos motins e das guerras significava a ruína da própria nação, ao mesmo tempo que cabia ao cronista do passado ensinar aos líderes e à sociedade do presente como evitar o malfeito de outrora.

Esse movimento discursivo acompanhou tanto a história como a literatura do século XIX, construindo um topos como método e padrão no tratamento da argumentação histórica. Assim como Cerqueira e Silva, também Domingos Antônio Raiol se esmerou na construção de um discurso histórico que movimenta um vasto campo narrativo eivado de sinonímias do cânone romântico, das passagens da vida como enredo, cilada, insídia, perfídia ou traição. A história Jacob Patacho possui então conteúdo e forma indissociáveis na interpretação e análise que acompanhou o presente artigo até aqui. Na história e na literatura, os acontecimentos deflagrados na Província do Grão-Pará durante a primeira metade do século XIX, envolvendo a figura de um anti-herói desertor, foram como cenografia de uma história malograda.

Enquanto isso, Inglês de Souza por meio de uma escrita que caminhava entre realismo e o naturalismo, testemunhou o passado a partir de uma série de transformaçôes sociais e políticas entre o final do Império e o limiar da República. Subjaz em seu texto, a crônica da história do Brasil como denúncia do descaso do governo nacional, tanto do Segundo Reinado, como da República, com a imensa região amazônica. Se a questão da distância das esferas do poder central e da própria crise de autoridade continua latente na intepretaçáo da Cabanagem em Raiol e Inglês de Souza, este último já observava o movimento da história a partir de uma república em construção e em crise. Portanto, as diferentes narrativas, entre a história, a crônica e a prosa literária, dialogam e estabelecem pontos de reflexáo com esses diversos contextos e conjunturas. Por isso mesmo, a construçâo de um personagem como

\footnotetext{
${ }^{60}$ PINHEIRO, Luís Balkar. Visões da Cabanagem: uma revolta popular e suas representaçôes na historiografia. Manaus: Valer, 2001; RICCI, Magda. Llagas de guerra y actos de fé política: la "Cabanagem” en la narrativa historiográfica y antropológica. Boletin Americanista, v. 1, p. 33-57, 2012; KOSELLECK, Reinhard. Futuro passado. Rio de Janeiro: Ed. PUC-Rio; Contratempo, 2006.
} 
Jacob Patacho certamente iria se distinguir ao longo do tempo e de acordo com a natureza de cada uma das três produçóes textuais aqui analisadas, muito embora o estigma do medo permanecesse incólume das diversas representaçôes.

Se pensarmos que Cerqueira da Silva absorveu a atmosfera dos movimentos políticos e sociais no contexto da Independência do Brasil no Pará, estabelecendo um texto que por vezes se trata de um "pacto autobiográfico" com a história vivida, ${ }^{61}$ Domingos Antônio Raiol voltou-se para a memória. O ethos biográfico desse autor esteve sempre marcado pela morte de seu pai, Pedro Antônio Raiol, em 1835, quando era vereador do Conselho Municipal de Vigia, no nordeste do Pará. A marca do assassinato do pai por rebeldes cabanos certamente serviu-lhe de esquadro, à luz de uma historiografia marcadamente romântica, para a composição de uma imagem do malfeitor Jacob Patacho. Infância e memória também se entrelaçariam na literatura de Inglês de Sousa. O quadrilheiro Patacho é descrito em romance a partir de um cenário das matas da cidade de Óbidos, no Baixo-Amazonas paraense, recuperado de um tempo perdido na lembrança do escritor. Até os 14 anos, Inglês de Sousa viveu a vida de uma antiga cidade colonial, com ares luso-amazônicos, a começar pelo nome, encravada em meio à floresta. Histórias da escravidáo, das lutas da Cabanagem, do mundo das fazendas de cacau, do dia a dia das comunidades de várzea estáo magistralmente desenhadas entre o realismo ficcional e o naturalismo cientificista. Para Inglês de Sousa, a quadrilha de Patacho é a um só tempo uma marca da sociedade que vivia à margem da civilização como também um registro fiel do cenário político do interior do Brasil no alvorecer da República. Uma pergunta ficava no ar: o que teria mudado do império à república em relação a esses homens sem senhor à margem das forças do Estado, algo como os masterless men e suas ideias radicais nos movimentos revolucionários ingleses do século XVII. ${ }^{62}$

Com efeito, e por tudo isso, queremos reiterar que as açôes do chamado "cangaceiro das águas" e seu "bando" ultrapassaram a memória oficial e popular da época, passando pelos compêndios de história, chegando ao romance e ao gosto burguês do final do século XIX, como nos ensinou Ian Watt. ${ }^{63} \mathrm{Na}$ obra ficcional de Inglês de Sousa, do mesmo modo, o principal nexo da narrativa e da memória esteve vinculado ao estigma da "violência" e da "criminalidade". Uma vasta cantilena e aplicaçáo do vernáculo do medo acompanhou o registro da história de Patacho e das lutas políticas do tempo regencial. Medo de ser roubado, medo de morrer queimado, medo de ter o corpo e a vida desonrados, medo da experiência subversiva ou simplesmente o medo da morte foram mais do que insights

${ }^{61}$ LEUJENE, Philippe. Le pacte autobiographique. Paris: Editions du Seuil, 1996.

${ }^{62}$ HILL, Christopher. The World Turned Upside Down: Radical Ideas during the English Revolution. Londres: Penguin, 1984.

${ }^{63}$ Ian Watt, num livro clássico de 1957, analisa as origens e sedimentações do romance, como gênero popular, na Inglaterra do século XVIII, levando em consideraçóes alguns pontos que julgamos importantes para o contexto brasileiro do século XIX, como a ascensão das camadas médias urbanas e da imprensa, uma retórica ligada ao individualismo econômico e ao progresso do capitalismo e também certa secularizaçáo da sociedade (WATT, 1990, especialmente os capítulos 1, 2, 6 e 10). 
da narrativa do passado. O malfeitor Jacob Patacho foi, na realidade, o exemplo do ethos que contribuiu para fixar na historiografia brasileira uma visão específica das populaçôes pobres e escravas no Pará durante o Segundo Reinado, marcada pelo sentimento de terror em tempos de revolução.

\section{Referências bibliográficas}

ARAÚJO, José Mourão de. Literatura e história na recepção crítica do conto de Inglês de Sousa. Dissertação (Letras) — Universidade Federal do Pará, Belém, 2006.

AUFDERHEIDE, Patricia Ann. Order and violence: social deviance and social control in Brazil, 1780-1840. Dissertação (PhD), University of Minnesota, 1976.

AZOULAY, Vincent; BOUCHERON, Patrick (Dir.). Le mot qui tue: une histoire des violences intellectuelles de l'antiquité à nos jours. Seyssel: Champ Vallon, 2009.

BACHELARD, Gaston. L'Intuition de l'instant. Paris: Stock, 1992.

BLAKE, Augusto Vitorino Alves Sacramento. Diccionario bibliographico brazileiro. v. 3, Rio de Janeiro: Imprensa Nacional. 1895.

CANDIDO, Antonio et al. A Personagem de ficção. São Paulo: Perspectiva, 2009.

CLEARY, David. "Lost altogether to the civilised world": race and the Cabanagem in Northern Brazil, 1750-1850. Comparative Studies in Society in Northern Brazil. v. 40, n.1, p. 109-135, 1998.

CERQUEIRA E SIVA, Ignacio Accioli de. Corografia Paraense ou Descripção Física, Historica, e Politica da Provincia do Gram-Pará. Salvador: Typografia do Diario, 1833.

. As Memorias historicas e politicas da provincia da Bahia. Bahia: Typ. do Correio Mercantil, 1835.

CHAUVAUD, Frederic (Dir.). Corps saccagés: une histoire des violences corporelles du siècle des lumières à nos jours. Rennes: Presses Universitaires de Rennes, 2009.

CHESNAIS, Jean Claude. Histoire de la violence em Occident de 1800 à nous jours. Paris: R. Laffond, 1981.

CHIAVENATO, José Júlio. Cabanagem: o povo no poder. São Paulo: Brasiliense, 1984.

COLÁS, Alejandro; MABEE, Bryan. Mercenaries, pirates, bandits and empires: private violence in historical context. Nova York: Columbia University Press, 2010.

COURTOIS, Martine (Dir.). Limaginaire du feu: approches bachelardiennes. Lyon: Jacques André, 2007.

CRUZ, Ernesto. Nos bastidores da Cabanagem. Belém: Oficina Gráfica da Revista de VETERINÁRIA, 1942. 
Medo, honra e marginalidade: imagens de Jacob Patacho na história e literatura do século XIX

DELUMEAU, Jean. História do medo no ocidente 1300-1800: uma cidade sitiada. São Paulo: Companhia das Letras, 2009.

DI PAOLO, Pasquale. Cabanagem: a revolução popular da Amazônia. 2. ed. Belém: Cejup, 1990.

FEBVRE, Lucien. Honra e pátria. Rio de Janeiro: Civilização Brasileira, 1998.

FERRO, Marc. Le ressentiment dans l'histoire: comprendre notre temps. Paris: Odile Jacob, 2007. FIGUEIREDO, Aldrin Moura de. Teias da memória: a Companhia de Jesus e a historiografia da Amazônia no século XIX. Varia Historia, Belo Horizonte, n. 23, p. 77-96, 2000.

- Memórias cartaginesas: modernismo, Antiguidade clássica e a historiografia da Independência do Brasil na Amazônia, 1823-1923. Estudos Históricos, Rio de Janeiro, v. 22, n. 43, p.176-195, 2009.

FOUCAULT, Michel. A ordem do Discurso. 8. ed. São Paulo: Loyola, 2005.

GINZBURG, Carlo. Medo, reverência e terror: quatro ensaios de iconografia política. São Paulo: Companhia das Letras, 2014.

GIORDANO, Umberto. Andrea Chénier: opera in four acts. Nova York: Opera Orchestra of New York, 1984.

GURSDORF, Georges. As revoluçôes da França e da América: a violência e a sabedoria. Rio de Janeiro: Nova Fronteira, 1993.

HÄBERLEIN, Mark. The Fuggers of Augsburg: Pursuing Wealth and Honor in Renaissance Germany. Charlottesville: University of Virginia Press, 2012.

HARRIS, Mark. Rebellion on the Amazon: the Cabanagem, race, and popular culture in the north of Brazil, 1798-1840. Cambridge: Cambridge University Press, 2010.

HARTOG, François. Regimes de Historicidade: presentismo e experiências do tempo. Belo Horizonte: Autêntica, 2013.

HILL, Christopher. The World Turned Upside Down: Radical Ideas during the English Revolution. Londres: Peguin, 1984.

HOBSBAWM, Eric. Bandidos. 4. ed. São Paulo: Paz e Terra, 2010.

HURLEY, Henrique Jorge. A Cabanagem. Belém: Livraria Clássica, 1936.

. Traços cabanos, Belém: Oficina Gráfica Instituto Lauro Sodré, 1936 a.

. Os cangaceiros das águas, Jacob Patacho. Revista do Instituto Histórico e Geographico do Pará, v. X, Belém: Off. Graphicas do Instituto Lauro Sodré, 1938.

. Noçôes de História do Brasil e do Pará. Belém: Officinas Graphicas do Instituto Lauro Sodré, 1938a.

KOSELLECK, Reinhard. Futuro passado. Rio de Janeiro: Ed. PUC-Rio; Contratempo, 2006. 
LIMA, Leandro Mahalem de. Rios Vermelhos. Perspectivas e posiçóes de sujeito em torno da noçáo de cabano na Amazônia em meados de 1835. Dissertação (Mestrado em Antropologia), Universidade de São Paulo, USP, 2008.

LIMA, Luciano Demetrius B. Motins Políticos e a historiografia imperial: a inserção de um intelectual amazônico nos quadros do IHGB. Almanack Braziliense, v. 12, p. 88-104, 2010. LANGFUR, Hal. The forbidden lands: colonial identity, frontier violence, and the persistence of Brazil's eastern Indians, 1750-1830. Stanford: Stanford University Press, 2006.

LEUJENE, Philippe. Le pacte autobiographique. Paris: Editions du Seuil, 1996.

MATTHEWS, Graham; GOODMAN, San (Eds.). Violence and the limits of representation. Nova York: Palgrave Macmillan, 2013.

MINISTRO da Guerra na Camara dos deputados. Diário do Rio de Janeiro, Ano XVIII, n. $147,05 / 07 / 1839$.

MOTT, Luiz. Sexualidade no Brasil Colonial. In: SÁ, Carlos (Org.). Sexualidade Humana. Rio de Janeiro: Revinter, 2000, p.117-129.

NUNES, Benedito. Narrativa histórica e narrativa ficcional. In: RIEDEL, Dirce (Org.) Narrativa: ficção \& história. Rio de Janeiro: Imago, 1988.

OLIVEIRA, Machado de. Sessão em 11 de julho de 1839. Annaes do Parlamento Brazileiro. Rio de Janeiro: Tipographia do Imperial Instituto Artístico, 1884.

PINA, Maria das Graças G. de. Cabanagem: "o vulcão da anarquia”?. Labirintos, v. 1, 2008, p. 1-14.

PINHEIRO, Luís Balkar. A revolta popular revisitada: apontamentos para uma história e historiografia da Cabanagem. Projeto História, São Paulo, v. 19, p. 227-241, 1999.

- Visóes da Cabanagem: uma revolta popular e suas representaçóes na historiografia. Manaus: Valer, 2001.

RAIOL, Domingos Antônio. Motins Politicos ou História dos Principais Acontecimentos Políticos na Província do Pará desde o ano de 1821 até 1835. v. II. São Luís: Typ. B. de Mattos, 1868.

RAMOS, Eliana. Em tempo cabanal: cidade e mulheres no Pará imperial — primeira metade do século XIX. Dissertação (História) — Pontifícia Universidade Católica, São Paulo, 1999.

REDDY, William. The invisible code: honor and sentiment in postrevolutionary France, 18141848. Berkeley: University of California Press, 1997.

REIS, Arthur Cezar Ferreira. Sintese de História do Pará. Belém: Revista de Veterinária, 1942.

RIBEIRO, Gladys Sabina. A liberdade em construção: identidade nacional e conflitos antilusitanos no Primeiro Reinado. Rio de Janeiro: Relume Dumará, 2002. 
RICCI, Magda. Do sentido aos significados da Cabanagem: percursos historiográficos. Anais do Arquivo Público de Belém, Belém, v. 4, p. 241-271, 2001.

. Um morto, muitas mortes: a imolação de Lobo de Souza e as narrativas da eclosão cabana. In: NEVES, Fernando; LIMA, Maria R. (Orgs.). Faces da história da Amazônia. Belém: Paka-Tatu, 2006, p. 519-544.

. Cabanagem, cidadania e identidade revolucionária: o problema do patriotismo na Amazônia entre 1835 e 1840. Tempo, Rio de Janeiro, v. 11, p. 15-40, 2006 a.

. Llagas de guerra y actos de fé política: la "Cabanagem" en la narrativa historiográfica y antropológica. Boletin Americanista, v. 1, p. 33-57, 2012.

ROCQUE, Carlos. Cabanagem: epopéia de um povo. Belém: Imprensa Oficial, 1984.

SOLENDER, Katherine. Dreadful fire: burning of the Houses of Parliament. Cleveland: Cleveland Museum of Art; Indiana University Press, 1984.

SCHMITT, Jean-Claude. A História dos marginais. In: LE GOFF, Jacques; CHARTIER, Roger (Orgs.). A história nova. 5. ed. São Paulo: Martins Fontes, 2005, p. 352-390.

SILVA, Renato Martins e. Em defesa da honra: um tema presente na literatura do século XIX. Anais do IV Congresso de Letras da UERJ. São Gonçalo, 2007, p.1-20.

SOUSA, Inglês de. O missionário. Rio de Janeiro: Laemert \& Cia, 1888. . Contos amazônicos. São Paulo: Editora Martin Claret, 2005.

STRANGE, Carolyn; CRIBB, Robert; FORTH, Christopher (Eds.). Honour, violence and emotions in history. Londres: Bloomsbury, 2014.

VELLASCO, Ivan de Andrade. A cultura da violência: os crimes na Comarca do Rio das Mortes - Minas Gerais Século XIX. Tempo, v. 9, n. 18, p. 171-195, 2005.

VIGARELLO, Georges. História do estupro: violência sexual nos séculos XVI-XX. Rio de Janeiro: Jorge Zahar, 1998.

WATT, Ian. A ascensão do romance. Sáo Paulo: Companhia das Letras, 1990.

WEISS, Max. Fear and Its Opposites in the History of Emotions. In: LAFFAN, Michael; WEISS, Max (Eds.). Facing fear: the history of an emotion in global perspective. Princenton: Princenton University Press, 2012, p.1-9.

WHITMER, Barbara. The violence mythos. Albany: State University of New York Press, 1997.

WILLIAMS, Raymond. Marxism and literature. Oxford: Oxford University Press, 1977. . Problems in materialism and culture: selected essays. Londres: Verso, 1980. 